\title{
Subtidal understorey algal community structure in kelp beds around the Cape Peninsula (Western Cape, South Africa)
}

\author{
Leliaert F.', R.J. Anderson'², J.J. Bolton ${ }^{3}$, and E. Coppejans' \\ ' Universiteit Gent, Vakgroep Biologie, Onderzoeksgroep Algologie, \\ K.L. Ledeganckstraat 35, 9000 Gent \\ E-mail: frederik.leliaert@rug.ac.be \\ 2 Seaweed Unit, Marine and Coastal Management \\ Private Bag X2, Roggebaai 8012, Cape Town, South Africa \\ ${ }^{3}$ University of Cape Town, Department of Botany \\ Rondebosch 7700, South Africa
}

The subtidal understorey seaweed communities were studied along a coastal distance of $104 \mathrm{~km}$ around the Cape Peninsula, which is situated in an overlap region between two marine provinces and characterized by a considerable temperature gradient. Sampling was carried out at six sites (4 to 10 quadrats per site) around the Cape Peninsula. For each of the quadrats, biomass of each species, grazing, and environmental variables such as temperature, wave exposure and sand cover were determined. The data were analysed using canonical correspondence analysis (CCA) and two way indicator species analysis (TWINSPAN). A total of 142 seaweed taxa were found at the six sites (21 Chlorophyta, 14 Phaeophyta and 107 Rhodophyta). The two sides of the Peninsula have a very different biomass-composition of Chlorophyta, Phaeophyta and Rhodophyta. The biomass of Rhodophyta in the Atlantic sites is much higher than in the Bay, and the biomass of Chlorophyta is higher in False Bay than on the west coast. A change in floristic composition of subtidal algal communities around the Cape Peninsula can be observed and is principally related to seawater temperature and wave exposure. Next to these physical factors, grazing is demonstrated to be important in determining species composition. A lower degree of wave exposure might result in a higher number of grazers in False Bay. The occurrence of a higher cover of encrusting corallines in the Bay is probably a consequence of the higher grazing pressure. Distinct community types can be recognized from TWINSPAN and CCA. 